Equality and the Duties of Procreators (March 16, 2001)

Children and Political Theory edited by David Archard and Colin MacLeod (Oxford University Press, 2002)

\title{
Peter Vallentyne
}

Abstract: I formulate and defend a theory of special procreative duties in the context of a liberal egalitarian theory of justice. I argue that (1) the only special duty that procreators owe their offspring is that of ensuring that their life prospects are non-negative (worth living), and (2) the only special duty that procreators owe others is that of ensuring that they are not disadvantaged by the procreators' offspring (a) violating their rights or (b) adversely affecting their equality rights and duties.

\section{Introduction}

What special duties do procreators have with respect to their offspring? Roughly speaking, I shall argue that (1) the only special duty that procreators owe their offspring is that of ensuring that their life prospects are non-negative (worth living), and (2) the only special duty that procreators owe others is that of ensuring that they are not disadvantaged by the procreators' offspring (a) violating their rights or (b) adversely affecting their equality rights and duties.

As we shall see, some of my claims are significantly at odds with common sense. I have been led to these views by an attempt to reconcile reflectively plausible moral principles with considered moral judgements in particular cases. Thinking about the moral status of children requires thinking about other non-autonomous beings with moral standing (non-human animals), 
and consistency here requires, I believe, some radical revision in how we think about children (as well as animals). Although I hope to provide enough justification to make my claims respectable, I have no illusions that my arguments will convince most readers. The prevailing judgements being challenged are extremely strong, and my arguments admittedly are not. So the most I can hope to accomplish here is to spell out and motivate a radical alternative to the received view.

\section{Background}

I shall assume—controversially—that with respect to adult-to-adult relations some form of moderate liberal egalitarianism is correct. More specifically, I shall assume that adults (agents) are protected by certain kinds of general rights of non-interference (e.g., negative rights of bodily integrity or self-ownership rights ${ }^{1}$ ), and that, subject to the constraints imposed by these rights, agents have some kind of limited general duty to others to promote the equality of life prospects (opportunities for a good life) to the extent that this is compatible with the (Pareto) efficient promotion of people's life prospects. Although this duty is based both on efficiency and on equality (and is thus not subject to the leveling down objection), for brevity I shall refer to it as the equality duty. Furthermore, there is, I shall assume, no general duty to assist other adults except as required by the general duty to promote equality—although, of course, there can be various special duties to assist (based on specific past acts, such as wrongdoings, commitments, etc.). Finally, I shall assume that agents who violate these rights have a duty to compensate their victims to the extent that they are responsible in some specified sense for the wrongful harms. The specification of the relevant conception of responsibility (e.g., for all causal effects or for only those that were reasonably foreseeable) has an enormous impact on the exact implications of the view I defend, but it would take me too far astray to attempt here to defend a particular conception thereof. For simplicity, I shall leave the qualifications about responsibility implicit, 
and when addressing specific cases we shall implicitly assume that the relevant responsibility conditions are met.

The above are, of course, controversial assumptions, but it is beyond the scope of this chapter to defend them here. Instead, I will address how children fit into this picture.

\section{General Duties to Children}

Although my main focus is on the special duties of procreators, I need first to discuss briefly what duties agents in general have to children. Because I shall argue in the next section that the special procreative duties to offspring are fairly minimal, it is important to note that this is in the context of very strong general duties owed to children (and others generally).

Childhood in the sense of non-adulthood can be understood in chronological terms (e.g., less than 18 years since birth), physical terms (e.g., physical capacities that normally only chronological children have), or mental terms (e.g., mental capacities that normally only chronological children have). I assume that for moral purposes it is mental childhood that matters, and that such childhood should be understood as non-agenthood, that is the nonpossession of a robust capacity for reflection upon, and modification of, beliefs, desires, and intentions. Hence, I shall include non-agent chronological adults (e.g., seriously mentally retarded adults) in the category of children.

Children, I claim, have, like adults, certain rights of non-interference and certain rights to have their life prospects improved by others when the demands of equality so require. I thus reject the view that only autonomous agents can have rights. According to this latter view-the choice-protection view of rights - the sole purpose of rights is the protection of autonomous choices. Since non-agents do not have the capacity for autonomous choices, they do not, it is claimed, have any rights, and thus others owe them no duties. Agents may have, on this view, 
duties to other agents with respect to non-agents, but there are no duties owed to non-agents.

This view simply does not make adequate sense of the duties that we have with respect to children (and other sentient animals). We have duties to - and not merely with respect toinfants and these are grounded in some kind of constraint protecting their interests. These duties are not impersonal duties (owed to no one), since children are owed compensation when these duties are violated. Nor are these duties owed to other agents, since they cannot be extinguished by all agents releasing each other from this duty. This view fails therefore to capture the sense in which the duty is indeed owed to the offspring. Furthermore, the fact that children cannot waive these duties, or even enforce them (e.g. use coercion to prevent infringement or to extract compensation), is quite irrelevant. The duties of others can be appropriately sensitive to the interests of children (e.g., the use of physical force against them is forbidden unless it is in their interest), and other agents can enforce the duties on behalf of the children. ${ }^{2}$

I agree that the choice-protection view captures the main sorts of rights that autonomous agents have. ${ }^{3}$ I see no good reason, however, to assume that there can only be one kind of right. Both conceptions of rights are coherent. The only question is which kind is relevant for a given kind of being. I claim that autonomous agents have (mainly) choice-protecting rights, and nonautonomous sentient beings have interest-protecting rights. Of course, as autonomy develops, the interest-protecting duties owed to children are gradually supplanted by choice-protecting duties owed to agents, but I shall not address the important issue of how and when this happens. ${ }^{4}$

Children, then, have some rights. But what rights do they have? We are, recall, assuming that agents have certain rights of bodily integrity (against non-consensual contact with the body) and certain equality rights. Children, I claim, have both as well—although understood in interestprotecting terms.

Consider first the interest-protecting right of bodily integrity. It is exactly like the adult 
right of bodily integrity except that non-harm to the holder (as opposed to consent) is required to justify contact. Giving an effective and needed vaccine to a 4-year old against her will does not violate her rights of non-interference, whereas it would normally violate those of an adult in that situation. Giving a pointless or needlessly dangerous injection to a 4-year old, on the other hand, does violate her rights of non-interference. The relevant conception of harm here is the long-term setback of interests. Thus, the mere presence of a short-term harm (the pain of the injection) is weighed against long-term benefits. Agents are permitted to impose short-term bodily harms on the child—as long as this imposes no net long-term disadvantage. ${ }^{5}$

Children, then, have certain general rights of non-interference. They also have, I claim, the same equality-based assistance rights that adults have. Agents have, we are assuming, some kind of limited duty to promote equality of opportunity for a good life. Children are included in the class of beneficiaries of this duty. Furthermore, there is no reason in principle to give children any special status within the class of beneficiaries. Of course, as a matter of fact, children typically occupy a privileged position with respect to equality. For they are especially vulnerable to suffering significant disadvantages through no fault of their own. Because of this vulnerability and because they typically have much longer potential life span compared with most adults, providing resources to children will typically provide a much larger and longer lasting benefit than the same provision to an adult. Hence, typically equality will be more efficiently promoted by devoting resources in very large part to needy children. This is, however, only a general tendency. Sometimes equality is better promoted by helping some opportunitydisadvantaged adults rather than by helping an opportunity-disadvantaged child (e.g. one for whom not much can be done). In addition, equality requires helping opportunity-disadvantaged adults before helping opportunity-advantaged children. In principle, however, children have the same equality rights as adults. 
The crucial point for what follows is that there are typically fairly strong equality-based duties that all agents have to help children. The duties of procreators must thus be understood in this context. I shall first discuss the special duties the procreators owe their offspring and then I shall discuss the special duties that procreators owe others.

\section{Special Duties of Procreative Parents to their Offspring}

What special duties do parents owe their offspring? We need here to distinguish between procreative and biological parents. Procreative parents are the people who bear ultimate responsibility in some appropriate sense for bringing the child into existence. In the normal case, the procreative parents are also the biological parents — the providers of sperm and egg — but this need not be so. Individuals who perform in vitro fertilization in fertility clinics, surrogate gestational mothers, and prospective guardian parents who arrange for these services to be provided, may be procreative parents. Determining exactly what kinds of actions generate procreative parenthood is a tricky matter, and I shall not attempt to offer an account here. The core case is the old-fashioned one where two people voluntarily have sex in full knowledge of the possibilities of conception taking place.

Biological parenthood does not generate any special duties with respect to their offspring. People who are raped and then forced to bear a child or who are cloned against their will do not have any special duties with respect to the offspring. It is rather those who voluntarily bring the offspring into existence who have, if any one does, such special duties. ${ }^{6}$ Procreative parenthood, that is, does generate special duties to the offspring. Although I shall focus on the procreation of human beings, the issues are, I believe, basically the same for the procreation of any kind of being with moral standing — for example sentient animals that one creates through breeding or in the laboratory. 
The only special procreative duties owed to one's offspring, I shall argue, are (1) the duty not to engage in procreative activity if there is "an unacceptable risk" that an offspring will be produced with negative initial life prospects, (2) the duty, if one engages in procreative activity, to "live up to the basic expectations", as they are at the time of the activity, for ensuring that the risk of offspring having negative initial life prospects is acceptable, and (3) the duty to compensate any offspring to the extent that their initial life prospects are negative.

The most central idea here is that of initial life prospects. The life prospects at given time, for a given individual, consist of the various possible futures that individual may have, each having a certain objective probability, given the prevailing social and natural circumstances. ${ }^{7}$ These probabilities reflect, for example, how the procreator and others are likely to behave towards the child (e.g., who will raise the child). Each of the possible futures yields a certain quality of life for the being. I leave open how the quality of lives is assessed, but I assume that a life has zero value for a person just in case it is equally valuable for that person as non-existence. Negative values are worse than non-existence. ${ }^{8}$ The value of these life prospects (the various possible futures) can, we shall assume, be evaluated, for example, based on their expected value. Life prospects can be evaluated at different times. The above duties appeal to the initial life prospects of an individual, where these are, I now stipulate, to be understood as those at the time that the individual acquires moral standing. Although I believe that humans acquire moral standing at sentience, I shall not here take a stance on that issue. ${ }^{9}$ The important point is that the initial life prospects are assessed relative to the time at which moral standing is acquired—and not (necessarily) relative to the time at which the organism comes into existence (at conception). Thus, for example, creating a human organism that would suffer terribly if she acquired moral standing (e.g., at sentience), does not generate negative initial life prospects if it is certain that she will die prior to acquiring moral standing. 
The first duty listed above is that of not engaging in procreative activity, if the risk of producing an offspring with negative life prospect is "unacceptable". I here offer no substantive account of the notion of an acceptable risk except to stipulate that $100 \%$ risk is unacceptable and $0 \%$ is acceptable. The problem here is quite general and not specific to procreation. If producing a given outcome (e.g., certain death by shooting) is wrong, what is the status of actions that impose a risk that you might produce that outcome (e.g., shooting at firing range)? I don't have a general view on this, and so I'm just going to leave it open. ${ }^{10}$ Obviously, a lot hangs on it.

The rough idea of the second duty above- the duty to "live up to the basic expectations" if one does engage in procreative activity—is this. If the procreator made some commitments concerning the child's life prospects, then he/she must honor them. In addition, if the conditions justifying the procreative activity (that the risk of negative initial life prospects were acceptable) were met in part because it was probable that the agent would perform certain actions (e.g., look after the child), then the agent has a duty to perform as many of those actions as necessary to ensure that agent does his part to meet the justificatory conditions. If the initial expectations only barely satisfied the justificatory conditions (acceptable risk of negative initial life prospects), then the basic expectations include almost all the initial expectations. If, however, the initial expectations significantly exceeded the justificatory conditions, then the procreator need only live up to enough of them so that the conditions would still have been met had they been based on the assumption that only these later actions would be performed. This is a fuzzy notion, and I won't attempt here to fill it in.

The third duty above - the duty to compensate any offspring to the extent that their initial life prospects are negative-requires those who impose a risk of negative life prospects (whether or not the risk is acceptable) to compensate their offspring for the negativity. Those who impose no risk of negative life prospects (probably an empty case in real life) have no duty to 
compensate their offspring for the quality of their lives (except, of course, to the extent they later wrong them).

The above claims are admittedly vague and require refinement. Rather than fine-tuning the claims, however, I will attempt to defend their general spirit. For simplicity, my defense will lump the above duties together under the heading "the duty to ensure non-negative life prospects", which is the core idea.

The proposed view takes a minimal view of special procreative duties to offspring. It is therefore worth being clear about what I am not claiming. First, I am not denying that it is morally desirable for procreators to help their offspring. Of course it is, and it typically makes sense for members of society to provide incentives for them to do so. Second, I am not denying that procreators typically have significant duties to help their offspring. Procreators may make binding commitments to each other or to others to help their offspring, and, if so, they have a duty to live up to their commitments. Furthermore, all agents have a duty to promote equality and, given that children are typically needy and procreators are typically in a position to benefit them significantly, procreators will typically have a duty to their offspring to help them in various ways. This duty, however, flows from an agent-neutral duty to promote equality and not in virtue of being their procreators. Third, I am not here claiming that there are no other procreative duties. I am only claiming that there are no other procreative duties owed to the offspring. Below we shall consider what duties are owed to others with respect to procreation. Finally, I am not assuming—indeed I reject the view—that procreators have a right to raise their offspring even if someone else would do a better job. ${ }^{11}$

The core claim is that the only special duty that procreators owe their offspring (as opposed to their general equality duties owed to them) is that of ensuring non-negative life prospects in the appropriate sense. Those who reject this view are likely to do so on the grounds 
that the recognized procreative duties are too weak. That is, most people will agree that having non-negative life prospects is necessary for permissible procreation, but most will deny that nothing more is owed to the procreated being. First, however, let us consider some objections that claim that the duties are too strong.

It might be claimed that agents are permitted to procreate no matter what the consequences for the offspring. One might hold this view, for example, on the grounds that there is a fundamental right to procreate. It is quite implausible, however, to hold that one is permitted to procreate no matter what the consequences for others. If there is a fundamental right to procreate, it, like all other rights, is constrained by the condition that one not violate the rights of, or directly and significantly harm, others. ${ }^{12}$

One might then claim that beings who do not currently exist have no rights, and so however the right to procreate is restricted, it is not restricted by duties owed to the offspring who are not currently alive. This objection does not question the duty to compensate existing offspring with negative initial life prospects. It only challenges the claim that a duty is owed to potential offspring not to engage in procreative activity-no matter how great the risk that they will have negative life prospects. For at the time of the activity, the potential offspring do not exist. This raises the well-known problem about how to make sense of our duties, if any, to beings who do not yet exist. ${ }^{13}$ There are several ways of trying to deal with this problem. One is to concede that there is no duty to refrain from engaging in activity that is likely to harm them later, but hold nonetheless that agents are liable for such harm if it comes about. Another is to hold that there is an impersonal duty to refrain from such activity. Another-the view that I would defend - is to hold that all duties are personal, and that empirically possible people have a kind of secondary moral standing that includes the right not to be created with negative life prospects. Defending this view, however, would take us too far astray. Hence, for simplicity, I 
shall focus on the claim that the sole special procreative duty is the duty-perhaps an impersonal one-not to create beings with negative initial life prospects. I shall not attempt to defend my claim that this duty is owed to the potential offspring. Even the weaker claim faces serious objections.

Even if one grants that we have a duty not to procreate under certain conditions, some will still question whether the duty is as strong as proposed. One might hold more weakly, for example, that we have the duty not to procreate only when the offspring will have negative life prospects and the negative benefits are not offset by benefits to others. On this view, it might be permissible to procreate where the benefit to others-e.g., the parents or other members of society—is sufficiently great. Utilitarians and unconstrained consequentialist egalitarians, for example, would take this view. The problem with this view is that it fails to recognize the moral separateness of persons (beings with moral standing). At least in the extreme cases where it involves a life not worth living, it is not permissible, except perhaps when necessary to avoid catastrophes, to make one person bear costs for the benefit of others. In more Kantian terms: it is impermissible to treat someone's very existence as a mere means of providing benefits to others.

The proposed view, I conclude, is plausible with respect to the duties that it recognizes. It also holds, however, that there are no further special procreative duties. Let us now consider objections to this claim.

The proposed view sets a fairly low life prospects standard that procreators must meet (mere non-negativity). There are many ways of setting a higher standard. One generic approach is to set an absolute standard, which is a standard that is not sensitive to the parental, social, or other circumstances. The proposed standard of non-negative life prospects is an example of an absolute standard, but higher absolute standards could be set by requiring (1) that all basic needs (nutrition, warmth, etc.) be met, or (2) that the life prospects be "adequate" or "decent", where 
this requires more than mere positivity (e.g., a level significantly above the zero level). ${ }^{14} \mathrm{~A}$ second generic approach imposes conditions that are comparative in the sense that they are sensitive to the life prospects of others. It might be required, for example, that procreators ensure that their child have the best or at least average life prospects compared with their cohorts. A third generic approach imposes conditions that are procreator-sensitive in the sense that they are sensitive to what the procreators are capable of providing. It might be required that procreators provide the best life opportunities that they can (without violating the rights of others) for their child, or perhaps the best that they can without significant (or major) sacrifice. ${ }^{15}$ Moreover, hybrid views are possible, such as an absolute or comparative approaches modified by the procreator-relative rider "to the extent possible without significant sacrifice by the procreators".

Pure procreator-relative (e.g., doing the best they can) and pure comparative approaches (e.g., ensuring at least average life prospects) on their own are too weak in that they do not require that the life prospects be non-negative. For, if the external circumstances are sufficiently dire (e.g., if essential resources are extremely scarce), or if the personal endowment of the offspring is sufficiently poor (e.g., unalterable severe pain), then even if the procreators do the best they can, and even if the child has the best life prospects of anyone (where everyone's prospects are negative), the child may still not have a life worth living. Let us therefore assume that the non-negative life prospects condition is accepted as a necessary condition, and that the only issue is whether additional conditions are plausible.

Absolute conditions that require more than non-negative life prospects (e.g., meeting basic needs) and comparative conditions (e.g., ensuring at least average life prospects) are too strong, if they are not qualified by some kind of procreator-relative condition on when it is permissible to procreate. For in situations in which it is possible to procreate with positive life prospects, but not possible to satisfy the additional absolute or comparative conditions, it is quite 
implausible to say that agents have an obligation to the prospective child not to let him/her acquire moral standing. For in this case the flawed existence is better for the child than no existence at all. So to be plausible, any additional condition on permissible procreation needs to have a qualification such as "to the extent possible" or perhaps "to the extent possible without significant sacrifice".

So the core objections to the proposed view are that procreative parents also have a duty to their offspring to ensure, to the extent possible (perhaps: without significant sacrifice) (1) that all the child's basic needs are met, (2) that the child has adequate life prospects, (3) that the child has at least average life prospects, or (4) that the child has the best achievable life prospects.

From an egalitarian position, however, there is a generic problem with procreative duties beyond the provision of non-negative life prospects. For, as noted above, unless they are made procreator-relative (e.g., to the extent possible for the procreator), it would follow that individuals have a duty to their offspring not to create them when the best they can do is provide the child with positive but substandard life prospects. This, however, is not plausible, given that positive prospects are, by definition, better than no life at all. Some sort of procreator-relative qualification is therefore needed — such as: to the extent possible, or to the extent possible without significant sacrifice, for the procreators. But if some such qualification is introduced, then there is a different problem. For with the procreator-relative qualification, the effective value of the rights of offspring against their procreators is higher the more advantaged their procreators are. From an egalitarian viewpoint, however, this is suspect. Why should children in advantaged families have effectively more valuable (although formally equal) rights than children in disadvantaged families? The most striking problem arises if procreators have a duty to provide the best life prospects they can for their offspring, but the same problem arises (although to a lesser extent) on the other views (e.g., if procreators have a duty to ensure 
adequate life prospects to the extent they can without significant sacrifice). Thus, egalitarians cannot accept a procreator-relative qualification, and without such a qualification, any duty more onerous than ensuring non-negative life prospects is implausible. Hence, from an egalitarian perspective - which I am assuming here - the duty to ensure non-negative life prospects is the only procreative duty owed to offspring.

Now, strictly speaking, this argument is too quick. For there is nothing troubling from an egalitarian perspective with some children having more valuable rights against their procreators compared with others_-as long as the total packages of rights they have (against any individual) are equally valuable. So, for example, there is nothing troubling in principle with rich children having more valuable rights against their procreators, as long this difference in value is offset by having less valuable rights against others (e.g., less valuable equality rights against others). So, if perfect equality will be achieved if everyone discharges their duties, then there need be no problem with some children having more valuable rights against their procreators.

The problem, however, is that perfect equality of opportunity may not be achievable, and that even if it is, the duties to promote equality may be limited and thus full compliance may not ensure that equality is achieved. In these cases, there is indeed something troubling about advantaged children having more valuable rights against their procreators. So, from an egalitarian perspective, there is a generic problem with imposing procreative duties to offspring beyond those of non-negative prospects. Instead, egalitarians should simply hold that the only procreative duty to offspring is that of ensuring that the offspring have non-negative life prospects. All agents have the further agent-neutral duty of promoting equality of life prospects. There is one other reason that some may think that the proposed special procreative duties to offspring are too weak. Why is it only at the time of procreation that the life prospects must be non-negative? Why not throughout the child's life, or at least up to the acquisition of 
adulthood (autonomy)? After all, even if the prospects are initially non-negative, things can go poorly later and life prospects can turn negative. One problem with requiring non-negative life prospects at each point in the life of offspring is that it holds procreators accountable for the selfregarding autonomous choices of their offspring once they are adults, and there is no reason in principle to hold parents so accountable. Procreators are not accountable for the mess that adult offspring make of their lives—although they are typically at least partially responsible for their disposition to do so, as reflected in their initial life prospects. Perhaps, then, procreators are accountable for ensuring positive life prospects at each point up to adulthood. The problem with this, however, is that it holds procreators accountable for the actions of others and for acts of nature during that period. Parents do indeed have duty to live up to their commitments and to the basic expectations for promoting the offspring's life prospects, but this does not require that life prospects be non-negative up to adulthood. If procreators do everything they are reasonably expected to do, and the offspring is unpredictably struck by lightning - thereby giving the offspring negative life prospects—-parents have no special procreative duty to ensure that life prospects become positive again (except to the extent this is part of their basic expectations). Of course, procreators, as well as others, have equality duties and this may indeed require them to help those struck by misfortune. It is not, however, a special procreative duty.

So far, we have considered procreative duties to the offspring. Let us now consider what duties to others procreation imposes.

\section{Special Duties of Procreative Parents to Others}

The only special procreative duties owed to others, I shall argue, concern (a) the possibility that one's offspring will violate the rights of others, and (b) the possibility that one's offspring will have initial life prospects that are sufficiently low (e.g., below average) that others will suffer 
either increased equality demands (to help the offspring) or reduced equality entitlements (because the offspring displace them in equality entitlements). In both cases there are three relevant duties: (1) the duty not to engage in procreative activity if there is "an unacceptable risk" of such possibility, (2) the duty, if one engages in procreative activity, to "live up to the basic expectations", as they are at the time of the activity, for ensuring that there is no "unacceptable risk" of such possibility, (3) the duty to provide compensation to those who are disadvantaged by the realization of such possibility—to the extent that one's procreative and later activities contributed to such realization. ${ }^{16}$

The crude idea is simple: One has a duty to ensure that others are not disadvantaged in certain ways by the presence of one's offspring. More specifically, there are two relevant kinds of disadvantage: rights violations and disadvantage in equality rights or duties. The latter kind of disadvantage can arise in either of two ways when the offspring is below average in initial life prospects. If the equality demands on each agent are limited in the amount of self-sacrifice that they require, then, if the offspring is sufficiently disadvantaged in initial life prospects, some individuals will cease to be entitled to help (because the offspring has a stronger claim to the help). If, on the other hand, the equality demands on each agent are not limited in the amount of self-sacrifice, then the second kind of equality disadvantage that can arise is that agents will have to make greater sacrifices to help the offspring in addition to helping the others.

If one procreates and one's offspring disadvantages others by violating their rights or by adversely affecting their equality rights and duties, then one has a duty to provide some compensation to the victims. ${ }^{17}$ The level of compensation owed, however, depends on how much one contributed to the risk of disadvantage. If, for example, one has an offspring that is virtually certain to violate rights of others (a highly hypothetical case, of course), then one would be liable for virtually all the wrongful harm one's offspring imposes. If, on the other hand, one has an 
offspring that is virtually certain to violate no rights (also a highly hypothetical case), then one would be liable for virtually none of the wrongful harm she imposes. Exactly how contribution is to be measured for these purposes is a tricky business, and I won't attempt to defend an account here. Nonetheless, the general idea should be clear enough.

It might seem strange to hold procreators accountable for the rights violations of their offspring when they are adults. Some authors have argued that parents should be liable for damages imposed by their minor offspring, ${ }^{18}$ but few, if any, have argued that the liability holds for adult offspring. Why should procreators be accountable for the choices that their offspring make as autonomous agents? In response to this concern, one could modify the proposed duty so that it holds only as a backup duty. If the offspring can be made to fully compensate their victims, then the procreators would not be liable. If, however, the offspring cannot be made to fully compensate their victims (e.g., if the offspring have died, disappeared, or simply do not have adequate resources), then the procreators would be liable for up to some amount based on their contribution to the risk of the rights violation. There is a fair amount of plausibility to this view, but I'm inclined to believe that it is less plausible than the proposed view. For, arguably, if adult offspring are predisposed to violate the rights of others, and this is due to genetic or environmental factors that the procreator contributed, it makes more sense to hold the procreator directly liable for the damages. This, of course, raises deep issues about free will and compatibilism, and hence I shall not attempt to defend this aspect of the proposed view. The core idea is that procreators are somehow accountable for some of the wrongful harms that their offspring inflict on others.

My claim, then, is that concern for rights violations by one's offspring and for equality disadvantages imposed by their presence are the sole bases for procreative duties owed to others. This view will be challenged as being too strong. I cannot, however, think of any minimally 
plausible reason to think that the view is too weak. It's not plausible, for example, to hold that procreation is impermissible, or that procreators are liable, merely because their offspring are not sufficiently likely to be virtuous or beneficial to others. Hence, we can consider only objections that the proposed view imposes too many obligations on procreators.

Why, one might ask, are procreators accountable for the impact of their procreation on people's rights and duties of equality? The advantages that equality rights bring and the disadvantages that equality duties bring vary depending on the circumstances, and there is no reason to suppose, one might argue, that people have a right not to have the value of these rights and duties affected by the actions of others.

Clearly, the procreated child has the same equality rights as others, and so the costs of compensating her for any equality disadvantages (at least if severe enough) should be born either by the procreators or by others (and not by her). The question is whether it must be born by the procreators. A plausible conception of the rights and duties of equality will, I claim, answer affirmatively. For, without such a duty, individuals would be free (under certain conditions) to procreate massive numbers of offspring (e.g., millions through cloning) who have lives barely worth living and significantly below average in life prospects. Given that such offspring have equality rights, this would lead to the impoverishment of all (since equality would require transferring resources to these poorly off individuals). Given the gross implausibility of the view that agents are permitted to do this, it seems clear that agents have a duty to cover the equality costs of their procreative activities. ${ }^{19}$

A second objection to the proposed view is that, although agents may have obligations not to procreate when the offspring are sufficiently likely to violate the rights of others, procreators bear no liability to provide any compensation to their victims. In this crude form, the objection is implausible. For at least in cases where the offspring are highly likely to engage in 
horrible rights violations (and the procreators know this), the procreators have an obligation to others not to procreate. Moreover, when one knowingly violates a duty to others, one is liable for providing compensation. At least in this case, liability for compensation is plausible, given that one wronged the individuals by procreating. A more sophisticated version of this objection grants that in cases of wrongful procreation procreators are liable for compensation, but it holds that individuals are not so liable when the act of procreation was permissible. Let us consider this objection more carefully.

Why should those who permissibly procreate be liable for compensating their offspring's' victims? The answer is that, in procreating, one imposes a risk on others that their rights will be violated. Imposing this risk may be permissible (and not violate a right of theirs) if the risk is acceptable (sufficiently low), but the permissibility thereof does not entail that one has no liability. ${ }^{20}$ Indeed, it is quite plausible — both in general and in the specific case of procreation - that those who impose risks of rights violations on others (even if permissibly) are liable for compensating them (if relevant responsibility conditions are met).

A third objection to the proposed view is that it imposes undue hardship on poor people, since they will have greater difficulty ensuring that the acceptability of the risk that their offspring will disadvantage others by rights violations or by impact on equality rights and duties. Not only do poor people have less money, their children also typically have lower life prospects and hence require more money to cover their equality costs. The problem is further exacerbated if children in poor families are more likely to engage in rights violations. To reply to this objection, we need to distinguish two cases. One is where the parents had at least average initial life prospects but as a result of their choices (bad choices, choosing leisure over wealth, unlucky gambles, etc.) ended up poor. Here the reply is that they will indeed be disadvantaged by the above accountability standards, but the disadvantage is the result of their own choices. Poor 
people are disadvantaged in all kinds of ways, but if those disadvantages are due to their own choices from an equal starting position, then there is nothing wrong with them suffering that disadvantage. The disadvantage of accountability for one's offspring is simply a special case. The second case is where the parents had less than average life prospects. Here, accountability for one's offspring exacerbates the disadvantage of the parents. In this case, the reply is that this disadvantage is taken into account in assessing the initial life prospects of the poor parents, and they will be entitled to some (perhaps very significant) equality-promotion benefits in virtue of this disadvantage. In principle, at least, such parents will suffer no net disadvantage.

\section{Conclusion}

The proposed view of special procreative duties agrees with common sense in that it holds it holds that agents have a duty not to procreate when the offspring's life prospects are negative. The rest of the view, however, is controversial. First, it holds (essentially) that there are no other special procreative duties owed to the offspring. There is no special procreative duty in this regard, for example, to ensure that one's offspring have life prospects that are as high as reasonably possible. Much of the counterintuitiveness of this position disappears, however, in the context of an egalitarian theory that holds that people have significant duties to promote people's life prospects by promoting the equality thereof. The duty to help one's offspring, on this view, is simply a special case of one's duty to help others. The second way that the proposed view departs from common sense is that it holds that procreators have duties to others to compensate them for disadvantages imposed by the existence of the offspring (from rights violations and from negative impact on equality rights and duties).

Throughout I have focused on rights and duties without any reference to whether they are enforceable - that is, to whether the use of force is permissible to ensure that the rights are 
respected or the duties fulfilled. I would argue that each of the rights involved (and all the duties on the proposed view are correlative to rights) are in principle enforceable. If this is right, then the state (and others) may in principle legitimately enforce these rights. It's worth noting, however, two qualifications. First, just as it is not permissible to enforce a choice-protecting right when the right-holder does not consent to the enforcement, it is also, I would argue, not permissible to enforce interest-protecting rights when the enforcement is not in the holder's interest. So, there may be some cases where the enforcement of children's rights is not permissible (preventing a parent from beating a child where the result of such prevention would be worse for the child). Second, that a right is permissibly enforceable does not entail that it is obligatory to enforce it. The duty to promote equality will impose some duties to enforce rights, but, where tradeoffs must be made in promoting equality, it will sometimes allow some rights violations not to be enforced.

Obviously, extending the proposed view to a theory of legitimate state (and individual) enforcement is the topic for another paper. Enough has been said, I hope, to make the position worthy of further development and examination. ${ }^{21}$ 


\section{References for Vallentyne's chapter}

Archard, D. (1993), Children: Rights and Childhood, New York: Routledge Inc.

Brennan, S. (2002), “Children's Choices or Children's Interests: Which Do their Rights Protect?”, this volume.

Buchanan, A., Brock, D., Daniels, N., and Walker, D., From Chance to Choice: Genetics and Justice, Cambridge: Cambridge University Press.

Calabresi, C. and Melmed, A. D. (1972), "Property Rules, Liability Rules, and Inalienability: One View of the Cathedral", Harvard Law Review 85: 1089-1128.

Casal, P. and Williams, A. (1995), "Rights, Equality, and Procreation”, Analyse \& Kritik 17: 93116.

George, R. (1987), "Who Should Bear the Cost of Children?", Public Affairs Quarterly 1: 1-42.

Heyd, D. (1992), Genethics: Moral Issues in the Creation of People, Berkeley: University of California Press.

Kramer, M. H., Simmonds, N.E., and Steiner H. (1998), A Debate over Rights, Oxford: Oxford University Press.

Lomasky, L. (1987), Persons, Rights, and the Moral Community, New York: Oxford University Press.

McMahan, J. (1998), "Wrongful Life: Paradoxes in the Morality of Causing People to Exist”, in Rational Commitment and Social Justice: Essays for Gregory Kavka edited by Jules L. Coleman and Christopher W. Morris, New York: Cambridge University Press.

Mill, J. S. (1859), On Liberty, Indianapolis: Bobbs-Merrill Co. (1956).

Nozick, R. (1974), Anarchy, State, and Utopia, New York: Basic Books.

O'Neill, O. (1988), “Children's Rights and Children's Lives”, Ethics 98: 445-463. 
Parfit, D. (1984), Reasons and Persons, Oxford: Oxford University Press.

Parfit, D. (1986), “Comments”, Ethics 96: 832-72.

Purdy, L. (1978), “Genetics and Reproductive Risk: Can Having Children be Immoral?”, in Laura Purdy, Reproducing Persons: Issues in Feminist Bioethics, Ithaca: Cornell University Press, (1996); originally published in Genetics Now, edited by John L. Buckley, Washington, DC: University Press of America, 1978.

Rakowski, E. (1991), Equal Justice, New York: Oxford University Press.

Roberts, M. (1998), Child versus Childmaker: Future Persons and Present Duties in Ethics and the Law, New York: Rowman \& Littlefield Publishers.

Ruddick, W. (1980), "Parents and Life Prospects," in Having Children edited by Onora O'Neill and William Ruddick, Oxford: Oxford University Press.

Ruddick, W. (1999), "Parenthood: Three Concepts and a Principle," in Morals, Marriage, and Parenthood: An Introduction to Family Ethics, Belmont, CA: Wadsworth Publishing Company.

Shiffrin, S. V. (1999), "Wrongful Life, Procreative Responsibility, and the Significance of Harm”, Legal Theory 5: 117 - 48.

Steinbock, B. and McClamrock, R. (1999), "When is Birth Unfair to the Child", in Morals, Marriage, and Parenthood: An Introduction to Family Ethics edited by Laurence D. Houlgate, Belmont, CA: Wadsworth Publishing Co.

Steiner, H. (1994), An Essay on Rights, Cambridge, MA: Blackwell Publishers.

Sumner, W. (1987), The Moral Foundation of Rights, Oxford: Oxford University Press.

Thomson, J. J. (1990), The Realm of Rights, Cambridge, MA: Harvard University Press

Vallentyne, P. (1998), “Critical Notice of G.A. Cohen's Self-Ownership, Freedom, and Equality”, Canadian Journal of Philosophy 28: 609-626. 
Vallentyne, P. (2000), "Left-Libertarianism: A Primer", in Left Libertarianism and Its Critics:

The Contemporary Debate, edited by Peter Vallentyne and Hillel Steiner, Palgrave Publishers Ltd.

Vallentyne, P. (2001), "Self-Ownership", Encyclopedia of Ethics, 2nd edition, edited by Laurence Becker and Charlotte Becker, Garland Publishing, forthcoming.

Vallentyne, P. (2002), “Childrearing Rights: The Child's Best Interest”, unpublished.

Woodward, J. (1986), “The Non-Identity Problem”, Ethics 96: 804-31. 
Notes

${ }^{1}$ For discussion of why some kind of rights of non-interference, and self-ownership rights in particular, are needed, see Vallentyne (1998, 2000, and 2001).

${ }^{2}$ For discussions of the issues between choice-protecting and interesting-protecting conceptions of rights, see Sumner (1987), Steiner (1994), Kramer, Simmonds, and Steiner (1998), and Brennan (2002). For skepticism about whether all duties (and imperfect duties in particular) owed to children can be captured by rights, see O’Neill (1988).

${ }^{3}$ I probably reject a pure choice-protecting theory of rights for agents. For I endorse softpaternalism, which allows infringements of rights so as to ensure that the agent is making an informed choice. I believe that justifying soft-paternalism probably requires invoking some interest-protecting considerations even in the case of agents. For simplicity, however, I ignore this point in what follows.

${ }^{4}$ The crucial point is that, once one becomes sufficiently autonomous for certain kinds of decisions, then one's consent is required to waive the right rather than mere non-harm. Although the capacity for well-being is still present, its moral significance is overridden by the capacity for autonomous choice when the latter is present.

${ }^{5}$ I assume throughout that the interest-protecting rights of children protect their interests directly in the sense that whether a right is infringed by a particular action is determined by the impact of that action on the holder's well-being. Rights so understood are not infringed when no harm is done to the holder. Indirect interest-protecting rights, by contrast, ground the content of rights in the instrumental benefits to the holder of having those rights, and such rights may be infringed 
even if the holder is not harmed. A full defense of the proposed view would thus require a defense of the direct view against indirect views.

${ }^{6}$ If there is a duty to share certain medical information (e.g., about vulnerability to various diseases) with those with whom we are closely genetically related, then biological parents have this duty with respect to their offspring. My claim should be understood as holding that biological parenthood imposes no special duties with respect to offspring that are not also imposed by on all those with comparable or greater genetic similarity (e.g., siblings).

${ }^{7}$ Throughout I assume the existence of objective probabilities. If there are no such things, then a more sophisticated account is needed in terms of epistemically warranted subjective probabilities.

${ }^{8}$ Many deny that one can make judgements about whether a life is better or worse than no life at all. See, for example, Heyd (1992, ch. 4). I shall not here attempt to defend this assumption, but see Roberts (1998, ch. 1) and Buchanan, Brock, Daniels, and Walker (2000, ch. 6).

${ }^{9}$ Because I hold that empirically possible beings can have a kind of secondary moral standing (that gives them a right not to be brought into existence with negative initial life prospects), I should, strictly speaking appeal here to primary moral standing, where this is understood as the kind of moral standing that only existing beings can have. For simplicity, however, I ignore this point.

${ }^{10}$ For discussion of whether risks of primary rights violation are rights violations, see Thomson (1990, 242-248) and Nozick (1974, 73-78).

${ }^{11}$ I would defend the view that (roughly) the right to raise a given child can be validly claimed by anyone for whom possession of the right is in the child's best long-term interest. See, 
Vallentyne (2002).

${ }^{12}$ For further discussion of how the right to procreate cannot be unconditional, see Archard (1993, ch. 8).

${ }^{13}$ For discussion of the person-affecting restriction in the context of possible future people, see, for example, Parfit (1984, Part IV; 1986), Woodward (1986), Heyd (1992), McMahan (1998), and Roberts (1998). (The Roberts work is an especially promising way of satisfying the personaffecting restriction.)

${ }^{14}$ If basic needs are sufficiently expansive and the criterion of adequacy for life prospects is sufficiently weak, a person could have adequate life prospects while having unmet needs. Nonetheless, on typical understandings the adequacy requirement entails the basic needs requirement. Lomasky $(1987,174)$ appeals to basic needs ("adequate to prepare the child to live as an independent project-pursuer". Mill (1859) appeals to both basic needs ("food for its body, [and] instruction and training for its mind", p. 128) and adequate life prospects ("the ordinary chances of a desirable existence”, p. 132). Shiffrin (1999) appeals to the absence of harms, where harms can be present even if life prospects are positive. Purdy (1978) appeals to both basic needs ("normal health", p. 46) and adequate life prospects (“minimally satisfying life”, p. 45). Steinbock and McClamrock $(1999,195)$ appeal to "decent chance of a good life".

${ }^{15}$ Ruddick's (1980, 130; and 1999, 247) Life Prospects Principle requires something like the best life prospects achievable without significant parental sacrifice.

${ }^{16}$ As with the discussion of procreative duties to offspring, I appeal to the general notion of an "acceptable risk" of primary rights violation and to the notion of basic expectations for ensuring that no unacceptable risks are imposed. See the brief discussion of these notions in the previous 
section.

${ }^{17}$ As in the previous section, I leave open here whether conditions of fault are also required for accountability.

${ }^{18}$ See for example, Rakowski (1991, 247).

${ }^{19}$ For further defense of the special procreative duty not to disadvantage others in their equality rights and duties, see Rakowski (1991, 152-54) and Casal and Williams (1995). Casal and Williams also argue (correctly) against the view that, where children are a public good, everyone has a duty to contribute towards the costs of raising them. This view is defended in George (1987). ${ }^{20}$ For discussion of the difference between property rules (which prohibit the activity) and liability rules (which permit it, but then holds the agent liable for damage), see Calabresi and Melmed (1972).

${ }^{21}$ For their insightful comments, I thank David Archard, Samantha Brennan, Paula Casal, Roger Crisp, Tony Ellis, Brad Hooker, Matthew Kramer, Colin MacLeod, Andy Mason, Trenton Merricks, Gene Mills, Eric Rakowski, Hillel Steiner, and Andrew Williams. 